\title{
PELATIHAN KESIAPSIAGAAN DAN MITIGASI BENCANA ANGGOTA TARUNA SIAGA BENCANA (TAGANA) DI KOTA TIDORE KEPULAUAN
}

\author{
Abd Hakim Husen ${ }^{1}$, Suhardi' ${ }^{2}$, Ismail Rahman ${ }^{3}$, Amran Nur ${ }^{4}$ \\ ${ }^{1,3,4}$ Fakultas Kedokteran, Universitas Khairun, Ternate \\ ${ }^{2}$ Fakultas Pertanian, Universitas Khairun, Ternate \\ email: hakimabdul253@gmail.com, ismail.rahman45@yahoo.com
}

\begin{abstract}
ABSTRAK
Taruna Siaga Bencana (TAGANA) adalah bagian dari pemerintah daerah wajib melaksanakan fungsinya dalam kesiapsiagaan penanggulangan bencana. Bencana adalah dampak dari suatu kejadian yang tidak dapat ditanggulangi dengan sumber daya setempat sehingga yang menjadi penting yaitu pemberian pelatihan kesiapsiagaan dan mitigasi kepada anggota relawan kemanusiaan dalam penanggulangan bencana untuk pengurangan resiko bencana. Pengabdian ini bertujuan untuk mengetahui efektifitas pelatihan Bantuan Hidup Dasar (BHD) terhadap tingkat pengetahuan anggota Taruna Siaga Bencana (TAGANA). Desain dan metode penelitian ini menggunakan quasi experiment dengan rancangan penelitian One-Group Pre test-Post test. Sampel pada penelitian ini adalah semua anggota Taruna Siaga Bencana (TAGANA) Kota Tidore Kepulauan dengan teknik pengambilan sampelnya menggunakan total sampling. Anggota Taruna Siaga Bencana (TAGANA) sebelum diberikan pelatihan dilakukan pre-test yang berhubungan dengan kesiapsiagaan bencana setelah itu melaksanakan pelatihan dan simulasi Bantuan Hidup Dasar (BHD) kemudian dilakukan evaluasi pelatihan dengan cara post-test kepada anggota Taruna Siaga Bencana (TAGANA). Pelatihan ini berlangsung selama satu hari. Data dianalisis dengan menggunakan uji Mann Whitney Test. Pada penelitian ini hasilnya menunjukan bahwa adanya perbedaan tingkat pengetahuan anggota Taruna Siaga Bencana (TAGANA) sebelum dilakukan pelatihan pengetahuan dan setelah dilakukan pelatihan tindakan simulasi Bantuan Hidup Dasar (BHD) dengan nilai $(p=0.000)$. Dari hasil pembahasan dapat disimpulkan bahwa pengetahuan anggota Taruna Siaga Bencana (TAGANA) sangat efektif dalam melakukan pertolongan untuk mengurangi korban dan tingkat resiko bencana.
\end{abstract}

Kata Kunci: Bantuan Hidup Dasar (BHD), Pengetahuan Anggota TAGANA, Kota Tidore.

\begin{abstract}
Disaster Preparedness Team (TAGANA) is part of regional government must perform their function in disaster preparedness. A calamity is the impact of an event that could not be overcome with resource local is important so that the training preparedness and mitigation to members of the humanity in disaster to disaster risk reduction. This service aims to determine the effectiveness of the Basic Life Support (BHD) training on the level of knowledge of members of the Disaster Preparedness Team (TAGANA). The design and method of this study used a quasi experiment with the One-Group Pre Test-Post-Test design. The sample in this study were all members of the Disaster Preparedness Team (TAGANA) of Tidore The Islands City with their sampling technique using total sampling. Members of the Disaster Preparedness Team (TAGANA) before being given training are carried out pre-tests related to disaster preparedness after that carry out training and simulation of
\end{abstract}


Basic Life Support (BHD) then training evaluations are conducted by means of a post-test to members of the Disaster Preparedness Team (TAGANA). This training lasts for one day. Data were analyzed using the Mann Whitney Test. In this study the results showed that there were differences in the level of knowledge of members of the Disaster Preparedness Team (TAGANA) before the knowledge training was carried out and after the Basic Life Support (BHD) simulation action training was conducted with a value $(p=0,000)$. From the results of the discussion it can be concluded that the knowledge of members of the Disaster Preparedness Team (TAGANA) is very effective in helping to reduce casualties and the level of disaster risk.

Keywords: Basic Life Support (BHD), TAGANA Members' Knowledge, Tidore City.

\section{PENDAHULUAN}

Indonesia merupakan suatu negera dengan beragam bencana. Hampir seluruh jenis bencana yang ada di dunia ini ada di Indonesia, mulai dari bencana yang korbannya puluhan orang sampai yang korbannya puluhan ribu orang. Jika dilihat kecenderungan kejadian bencana yang selang waktunya makin pendek dan kejadiannya makin sering ini, maka diperkirakan kejadian seperti itu akan berlanjut pada tahun yang akan datang. Atas dasar prediksi tersebut maka dibutuhkan cukup pengetahuan dan keterampilan untuk menangani bencana dimasa mendatang (Perdana, 2016).

Tahun 2008, laporan United Nations Developments Program (UNDP) menyebutkan bahwa $40 \%$ dari total bencana alam di dunia terjadi di Asia dan lebih dari 80\% korban bencana alam tersebut tinggal di kawasan ini. Data dan informasi bencana dari BNPB dituliskan tentang bencana terbaru yang terjadi di Indonesia seperti letusan Gunung Sinabung di Sumatera Utara, gempa bumi di Malang, banjir di Bandung, tanah longsor di Trenggalek dan masih banyak bencana yang terjadi akhir-akhir ini (Damayanti dkk., 2017).

Maraknya bencana yang terjadi di Indonesia beberapa tahun terakhir, baik bencana alam maupun bencana karena ulah manusia disamping terjadinya keadaan kegawat-daruratan sehari-hari yang makin meningkat baik kuantitas, kualitas, dan intensitas kejadian. Hal ini menyadarkan kita semua perlunya menata pelayanan kesehatan emerjensi secara efektif, efisien, dan terstruktur (Departemen Kesehatan RI, 2004).

Kesiapsiagaan yang rendah mengakibatkan kondisi yang rentan atau kerentanan dan merupakan salah satu faktor terjadinya sebuah bencana. Bencana dapat terjadi akibat interaksi antara bahaya (hazard), kerentanan (vulnerability), kapasitas (capacity), dan risiko (risk). Risiko merupakan hasil dari interaksi dari ketiga faktor bencana lainnya. Secara sistematis risiko berbanding lurus dengan bahaya dan kerentanan, serta berbanding terbalik dengan kapasitas. Kerentanan yang tinggi akan menghasilkan 
risiko yang tinggi. Risiko yang tinggi akan sebanding dengan luasnya dampak akibat bencana (Istiqomah, 2015).

Menurut Oktari dan Kurniawan (2016), kesiapsiagaan merupakan tanggungjawab bersama para stakeholder, mulai dari pemerintah pusat, pemerintah daerah, masyarakat serta dunia usaha. Peran pelaku tersebut di atur dalam UU. No. 24 Tahun 2007 Tentang Penanggulangan Bencana. Salah satu stakeholder yang bertanggungjawab melaksanakan upaya kesiapsiagaan adalah Puskesmas (LIPI, 2011).

Tujuan pemberian pelatihan kesiapsiagaan dan mitigasi kepada Taruna Siaga Bencana (TAGANA) karena penting dalam penanggulangan resiko bencana, maka dari itu penulis merasa perlu untuk dilakukan penelitian tentang bagaimana keefektifitasnya pelatihan kesiapsiagaan dan mitigasi terhadap tingkat pengetahuan Taruna Siaga Bencana (TAGANA) dalam penanggulangan resiko bencana di Kota Tidore Kepulauan.

\section{METODE}

\section{Lokasi dan Rancangan Penelitian}

Penelitian ini dilakukan pada anggota Taruna Siaga Bencana (TAGANA). Metode penelitian ini adalah jenis penelitian quasi experiment dengan rancangan One-Group Pre test - Post test yang mengungkapkan sebab akibat dengan cara melibatkan satu kelompok subyek. Kelompok subyek diobservasi sebelum dilakukan intervensi kemudian diobservasi lagi setelah intervensi. Pengujian sebab akibat dengan cara membandingkan hasil pre-test dengan post test.

\section{Populasi dan Sampel}

Populasi dalam penelitian ini keseluruhan objek penelitian yang akan diteliti. Populasi dalam penelitian ini adalah anggota Taruna Siaga Bencana (TAGANA). Jumlah populasi dari penelitian ini adalah 50 anggota Taruna Siaga Bencana (TAGANA) Kota Tidore Kepulauan. Sampel dalam penelitian ini adalah seluruh anggota Taruna Siaga Bencana (TAGANA). Sampel diambil dengan menggunakan teknik total sampling, dimana total sampling merupakan teknik penentuan sampel bila semua anggota populasi digunakan sebagai sampel.

\section{Metode Pengumpulan Data}

Pengumpulan data dalam penelitian ini yaitu dengan cara menemui langsung responden dan mengedarkan formulir identitas pribadi serta persetujuan mengikuti penelitian. Untuk mengukur 
Tingkat Pengetahuan anggota Taruna Siaga Bencana tentang kesiapsiagaan dan mitigasi dalam Bantuan Hidup Dasar (BHD) maka menggunakan soal pre test dan post test sedangkan untuk tindakan dengan melakukan observasi. Responden dipilih berdasarkan pada suatu pertimbangan tertentu yang dibuat oleh peneliti berdasarkan ciri atau sifat-sifat sampel yang sudah ditentukan sebelumnya.

\section{Pengelolaan Data dan Analisis Data}

Data yang terkumpul diolah dengan menggunakan program SPSS. Uji statistik yang digunakan yaitu uji Mann Whitney. Uji Mann Whitney adalah Uji yang digunakan untuk menguji dua sampel independen atau lebih dengan bentuk data ordinal, dimana hubungan antara dua variabel yaitu dalam hal ini efektifitas pelatihan dengan tingkat pengetahuan, sikap dan tindakan.

\section{PEMBAHASAN}

Kegiatan pengabdian masyarakat tentang "Pelatihan Mitigasi dan Kesiapsiagaan Bencana Terhadap Taruna Siaga Bencana (TAGANA) di Kota Tidore Kepulauan" yang dilaksanakan pada hari Sabtu tanggal 19 Oktober 2019 pukul 08.00-15.00 WIT, bertempat di kantor lurah Kota Tidore. Peserta dalam kegiatan ini bukan hanya dari anggota Taruna Siaga Bencana (TAGANA), tetapi ikut juga berpartisipasi anggota dari Badan Penanggulangan Bencana Daerah (BPBD) Kota Tidore Kepulauan. Kegiatan ini mendapatkan antusias yang sangat tinggi dari anggota TAGANA dan BPBD Kota Tidore Kepulauan. Harapan peserta agar kegiatan seperti ini harus sering dilakukan dan disimulasikan agar meningkatkan keterampilan dan mitigasi dalam menghadapi bencana.

Berdasarkan hasil analisis dari 50 orang peserta yang mengikuti pelatihan terdapat peningkatan pengetahuan yang baik. Setelah diberikan pelatihan dan simulasi BHD maka nilai pengetahuan baik meningkat sebanyak 40 orang dan kurang 10 orang.

Pengetahuan anggota Taruna Siaga Bencana (TAGANA) tentang penanggulangan bencana sangat penting dimiliki dalam persiapan penanggulangan bencana, dengan pengetahuan bencana yang baik, yang dimiliki oleh seorang relawan baik dari pendidikan formal maupun pendidikan non-formal serta pengalaman-pengalaman penugasan dari relawan setidaknya membuat anggota tersebut untuk berfikir jauh kedepan terkait hal-hal yang mungkin saja pernah menjadi pengalaman sebelumnya, sehingga dapat membuatnya lebih waspada dan siap siaga dalam menghadapi bencana. Dengan adanya kegiatan pelatihan ini anggota Taruna Siaga Bencana (TAGANA) dapat memahami tentang pengertian evakuasi itu sendiri terlebih khusus untuk menolong korban yang mengalami henti jantung dan henti 
nafas. Efektifitas pelatihan kesiapsiagaan dan mitigasi terhadap tingkat pengetahuan harus sering diberikan simulasi Bantuan Hidup Dasar (BHD), agar selalu siap siaga dalam memberikan pertolongan.

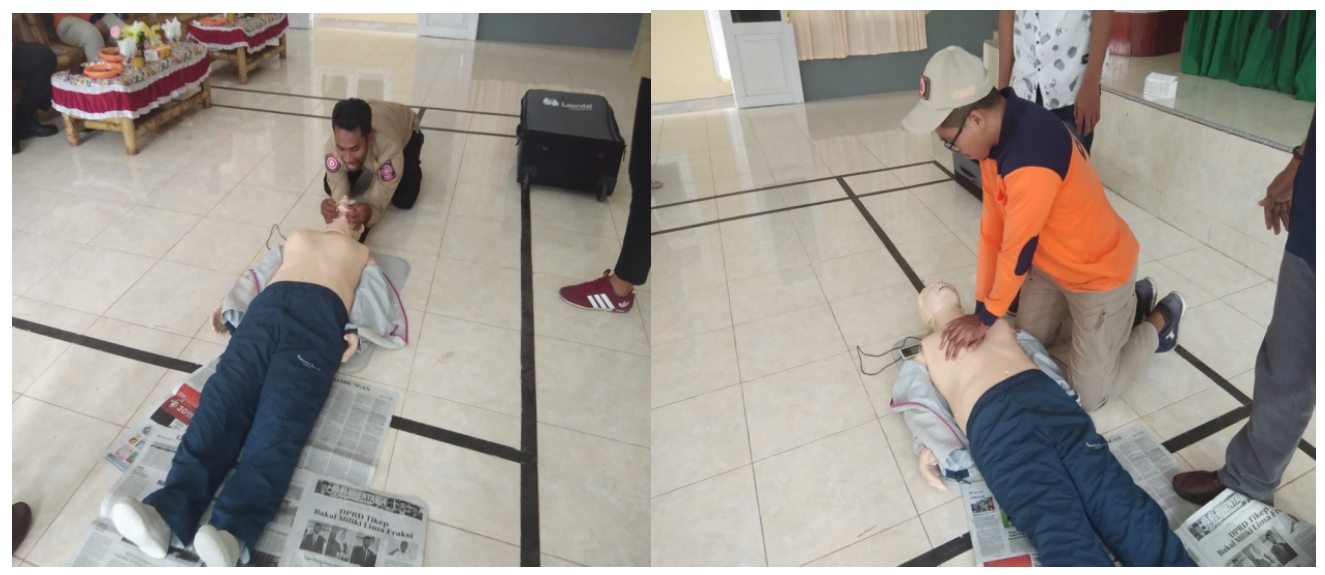

Gambar 1. Praktek buka jalan nafas Gambar 2. Praktek Resusitasi Jantung Paru (RJP)

\section{SIMPULAN}

Berdasarkan hasil pelatihan kesiapsiagaan dan mitigasi dalam hal ini memberikan Bantuan Hidup Dasar (BHD) terhadap anggota Taruna Siaga Bencana (TAGANA), dapat dilihat kurangnya sumber daya manusia yang akan ikut mewarnai pelayanan bantuan dan pertolongan korban bencana alam. Kemudian banyak juga anggota yang memiliki kompetensi di bidang bencana dan kegawatdaruratan yang sudah tidak aktif lagi menjadi Taruna Siaga Bencana (TAGANA). Oleh karena itu pemberian Bantuan Hidup Dasar (BHD) memberi konstribusi dalam menentukan kualitas kesiapsiagaan dan mitigasi dalam menghadapi bencana. Pelatihan ini juga dinyatakan efektif karena adanya peningkatan pengetahuan sehingga dapat menambah wawasan dan ilmu tentang bencana, dampak yang terjadi akibat bencana serta melakukan pertolongan kepada korban.

\section{DAFTAR PUSTAKA}

Damayanti D., Wahyu P.RG., Muhanni'ah. 2017. Hubungan Pengetahuan Tentang Manajemen Bencana Dengan Prevention Masyarakat Dalam Menghadapi Bencana Gunung Meletus Pada Kepala Keluarga Di Rt 06/Rw 01 Dusun Puncu Desa Puncu Kecamatan Puncu-Kediri. Jurnal Ilmu Kesehatan 5(2): 72-83.

Departemen Kesehatan RI. 2004. Sistem Penanggulangan Gawat Darurat Terpadu (SPGDT). Jakarta. 
Jurnal Pengamas, Vol.3, No.1, Juni (2020) e-ISSN: 2622-383X

Istiqomah Z. 2015. Kesiapsiagaan Bencana Puskesmas Di Kecamatan Suboh Kabupaten Situbondo. Universitas Jember.

LIPI. 2011. Ekologi Ternate. eds. Ibnu Maryanto and Hari Sutrisno. Jakarta: LIPI Pres.

Oktari, R. S., Kurniawan H. 2016. Framework Ketahanan Puskesmas Dalam Menghadapi Bencana. : $44-52$.

Perdana, N. 2016. Menurunkan Resiko Bencana. ed. Andi M. Akhmar dan M. Nawir. Makassar: Masaggena Press. 